\title{
Thalamic volumes in patients with bipolar disorder
}

\author{
Katrin Radenbach • V. Flaig - T. Schneider-Axmann • \\ J. Usher · W. Reith · P. Falkai - O. Gruber · \\ H. Scherk
}

Received: 17 January 2009/ Accepted: 12 January 2010/Published online: 3 February 2010

(C) The Author(s) 2010. This article is published with open access at Springerlink.com

\begin{abstract}
There are several hypotheses on functional neuronal networks that modulate mood states and which might form the neuroanatomical basis of bipolar disorder. The thalamus has been reported to be a key structure within the circuits that modulate mood states and might thus play an important role within the aetiology of the bipolar affective disorder. Nevertheless, structural brain imaging studies on the thalamus volume of bipolar patients have shown heterogeneous results. Using structural MRI scanning, we compared the thalamus volume of 41 euthymic bipolar patients to the thalamus volume of 41 well-matched healthy controls. Taking the concomitant medication as a co-variable within the patient group, the analysis of variance revealed a significantly smaller relative volume of the right thalamus in patients not treated with lithium when compared with healthy controls. In contrast, there are no significant differences concerning the thalamus volume between all euthymic bipolar patients and healthy controls. The study only shows findings of a transverse section. No longitudinal analysis was performed. More detailed information on patients' pharmacological histories could not be obtained. In conclusion, this result may be interpreted as an indication of the
\end{abstract}

K. Radenbach $(\bowtie)$ · V. Flaig · T. Schneider-Axmann ·

J. Usher · P. Falkai - O. Gruber · H. Scherk

Department of Psychiatry and Psychotherapy,

Georg-August-University Goettingen,

von-Siebold-Str. 5, 37075 Goettingen, Germany

e-mail: kradenb@gwdg.de

W. Reith

Department of Neuroradiology,

Saarland University Hospital, 66421 Homburg, Germany

H. Scherk

AMEOS Klinikum Osnabrueck, Knollstr. 31,

49088 Osnabrueck, Germany impact of the thalamus in the pathogenesis of the bipolar I disorder and emphasises the need for further longitudinal studies in bipolar patients with special attention paid to the concomitant medication, in particular to the role of lithium.

Keywords Bipolar affective disorder - MRI · Thalamus volume $\cdot$ Lithium

\section{Introduction}

There are several hypotheses on functional neuronal networks that modulate mood states and which might form the neuroanatomical basis of bipolar disorder. Two suggested loops of mood-regulation are (1) the so-called limbicthalamic-cortical circle consisting of the amygdala, the mediodorsal nucleus of the thalamus and the medial and ventrolateral prefrontal cortex, and (2) the so-called limbic-striatal-pallidal-thalamic circle which includes the striatum, the ventral pallidum and the above-mentioned anatomical structures of the limbic-thalamic-cortical circle [23]. The thalamus has been reported to be a key structure within these circuits that modulates human emotional, cognitive and social behaviour [24]. It serves as a relay station to the cerebral cortex and to limbic structures [9], as a "critical node" in forebrain circuitry [23], and it processes sensory information and integrates activity within areas of the forebrain.

In patients with bipolar disorder, the functioning of their emotional, cognitive and social behaviour can be disturbed [24]. The thalamus might, therefore, be a key structure linked to the aetiology of bipolar disorder [23]. This presumption is supported by several case reports [2, 8, 25], e.g. a patient presenting a transient manic mood state after an ischaemic lesion in both dorsolateral thalami [2] or a 
co-occurrence of mania and hemichorea after a right thalamic infarction [8].

Despite extensive research efforts in the last years, the neuropathogenesis of bipolar disorder remains poorly understood. So far, it might be described as a dysfunction in anterior sub-cortico-prefrontal limbic networks, specifically within the prefrontal-striatal-thalamic circuits and interconnected areas such as the amygdala and the midline cerebellum. Structural changes in these loops and the interconnected areas may lead to their dysfunction and to the development of affective disorders [19] on the basis of a so-called structural vulnerability. Several authors attempted a characterisation of structural changes in patients with bipolar disorder and mood disorders in general in review articles and meta-analyses. Overall, the results of structural brain abnormalities in bipolar patients, adults and children/ adolescents were inconsistent and varied considerably. With regard to thalamus volume, reviews and meta-analyses showed inhomogeneity $[12,19,24]$. In the most recent metaanalysis, Kempton et al. [10] reported no significant changes.

Taken together, changes in thalamus volume in bipolar patients seem to underlie more differentiated modulations than solely the diagnosis of a bipolar affective disorder. More concise studies with clinical subsamples defined by symptom profile, chronicity, severity and medication status are needed to clarify the current heterogeneous findings [19].

The aim of this study was to examine the thalamus volume of a large sample of well-matched euthymic patients with bipolar I disorder in comparison to healthy controls by structural brain imaging with special interest to the co-variable of lithium treatment. Other co-variables were the age of onset of the disease, number of previous manic or depressive episodes, medication with mood stabilizers other than lithium, antipsychotic medication and prior psychotic symptoms. On the basis of this matched sample, we were able to minimise the potential influence of gender, handedness, age, education and manic or depressed episodes on the thalamus volume, and to try to answer the question of whether structural changes emerge only in distinct subgroups of bipolar patients.

\section{Methods}

\section{Subjects}

Forty-one euthymic patients with bipolar I disorder and 41 healthy controls matched with respect to age, gender, handedness and education participated in the study (see Table 1). In this sample, the age of onset of the disease was 28.6 ( \pm 9.6$)$ years, duration of illness was 13.9 $( \pm 10.6)$ years and patients exhibited on average $7.9( \pm 8.3)$ manic and $7.9( \pm 7.6)$ previous depressive episodes. The scores of the MADRS [15] (4.6 \pm 3.5$)$ and YMRS [28] $(2.5 \pm 2.8)$ scales indicated the patients' euthymic mood state. 15 patients received lithium; 26 never received lithium, but amongst these 11 received other mood stabilizers, 4 first- and 14 second-generation antipsychotics. In total, 14 patients received antidepressants, of whom 5 were taking lithium. All patients were on stable medication at the time of imaging. The patients receiving lithium had been on a stable dose for at least 6 months. Lithium serum levels were obtained in the same week as the MRI scan. Between patients with and without lithium treatment, there was no significant difference in age at the time of the MRI scan $(F=1.4, d f=1,37, P=0.24)$, education $(F=1.6$, $d f=1,37, P=0.21)$, age of onset of the disease $(F=0.2$, $d f=1,35, \quad P=0.64), \quad$ duration of illness $\quad(F=1.4$, $d f=1,37, P=0.24)$, number of manic episodes $(F=0.1$, $d f=1,34, P=0.78)$, number of depressive episodes $(F=$ $0.1, d f=1,34, P=0.82)$, MADRS $(F=1.9, d f=1,34$, $P=0.18)$, YMRS $(F=0.7, d f=1,33, P=0.41)$ or family history for psychiatric diseases $\left(\chi^{2}=4.5, d f=2\right.$, $P=0.11)$.

Written informed consent was obtained from all subjects prior to their inclusion in the study and the study was approved by the local ethics committee and, therefore, performed in accordance with the ethical standards laid down in the 1964 Declaration of Helsinki. Patients with bipolar disorder were consecutively recruited from the outpatient unit of the Department of Psychiatry and Psychotherapy of the Saarland University Hospital between December 2003 and October 2006. The diagnosis of bipolar I disorder was confirmed using the German version of the Structural Clinical Interview for DSM-IV [26]. Patients with any other axis I disorder in particular alcohol dependence and medical and neurological illnesses that might have an influence on brain structure were excluded. The healthy controls exhibited no past or present psychiatric, neurological or medical disorder and had no positive family history of psychiatric disorders. They were recruited from the general population via advertising in newspapers.

Imaging

Magnetic resonance imaging scanning was performed on a 1.5-T Magnetom (Siemens, Erlangen). A T1-weighted, MPRAGE sequence $(\mathrm{TE}=4.42 \mathrm{~ms}, \quad \mathrm{TR}=1,900 \mathrm{~ms}$, $\mathrm{TI}=700 \mathrm{~ms}$, flip angle $\left.=15^{\circ}, \mathrm{FOV} 256 \times 256 \mathrm{~mm}\right)$ of 176 consecutive slices was acquired with a voxel size of $1 \mathrm{~mm}^{3}$. The images were re-orientated and aligned parallel to the anterior-posterior commissural axis and the origin was set to the anterior commissure. To measure the thalamus volume, the software MRIcro by Chris Roden was used. A rater blind to diagnosis and genotype (VF) determined the thalamus volume by direct manual tracing of the 
Table 1 Comparison of demographical and clinical data regarding healthy controls (HC), the total sample of bipolar patients (BP) and its two subsamples with lithium-treated (Li) and non lithium-treated (non-Li) patients

\begin{tabular}{|c|c|c|c|c|c|c|}
\hline & \multirow{2}{*}{$\begin{array}{l}\text { Controls } \\
\mathrm{HC}\end{array}$} & \multicolumn{3}{|c|}{ Bipolar patients } & \multirow[b]{2}{*}{$\begin{array}{l}\mathrm{HC} \text { versus } \\
\mathrm{BP}(P)\end{array}$} & \multirow[b]{2}{*}{$\begin{array}{l}\text { Non-Li } \\
\text { versus } \mathrm{Li}(P)\end{array}$} \\
\hline & & BP total & $\begin{array}{l}\text { Subsample } \\
\text { non-Li }\end{array}$ & $\begin{array}{l}\text { Subsample } \\
\mathrm{Li}\end{array}$ & & \\
\hline Number of participants & 41 & 41 & 24 & 15 & & \\
\hline Gender (female/male) & $20 / 21$ & $21 / 20$ & $12 / 12$ & $8 / 7$ & $0.83^{\mathrm{b}}$ & $0.84^{\mathrm{b}}$ \\
\hline Handedness (right/not right) & $32 / 9$ & $36 / 5$ & $21 / 3$ & $14 / 1$ & $0.24^{\mathrm{b}}$ & $0.56^{\mathrm{b}}$ \\
\hline Age (in years) (mean $\pm \mathrm{SD}$ ) & $42.2 \pm 10.8$ & $43.2 \pm 12.2$ & $41.1 \pm 12.8$ & $45.9 \pm 11.3$ & $0.70^{\mathrm{a}}$ & $0.24^{\mathrm{a}}$ \\
\hline Education proband (in years) (mean $\pm \mathrm{SD}$ ) & $14.2 \pm 2.7$ & $14.1 \pm 2.9$ & $14.5 \pm 2.8$ & $13.3 \pm 3.0$ & $0.84^{\mathrm{a}}$ & $0.21^{\mathrm{a}}$ \\
\hline Education father (in years) (mean $\pm S D$ ) & $12.9 \pm 2.3$ & $13.0 \pm 2.6$ & $13.2 \pm 2.7$ & $12.9 \pm 2.5$ & $0.89^{\mathrm{a}}$ & $0.72^{\mathrm{a}}$ \\
\hline Education mother (in years) (mean $\pm \mathrm{SD}$ ) & $11.0 \pm 2.1$ & $11.1 \pm 2.2$ & $11.4 \pm 2.2$ & $10.6 \pm 2.2$ & $0.87^{\mathrm{a}}$ & $0.32^{\mathrm{a}}$ \\
\hline Age of onset (in years) (mean \pm SD) & & $28.6 \pm 9.6$ & $28.0 \pm 9.9$ & $29.5 \pm 9.3$ & & $0.64^{\mathrm{a}}$ \\
\hline Duration of illness (in years) (mean $\pm \mathrm{SD}$ ) & & $13.9 \pm 10.6$ & $12.3 \pm 10.5$ & $16.5 \pm 10.5$ & & $0.24^{\mathrm{a}}$ \\
\hline Previous manic episodes (mean $\pm \mathrm{SD}$ ) & & $7.9 \pm 8.3$ & $8.2 \pm 8.5$ & $7.4 \pm 8.3$ & & $0.78^{\mathrm{a}}$ \\
\hline Previous depressive episodes (mean $\pm \mathrm{SD}$ ) & & $7.9 \pm 7.6$ & $7.7 \pm 7.4$ & $8.3 \pm 8.1$ & & $0.82^{\mathrm{a}}$ \\
\hline MADRS (mean $\pm \mathrm{SD}$ ) & & $4.6 \pm 3.5$ & $5.2 \pm 3.1$ & $3.5 \pm 3.9$ & & $0.18^{\mathrm{a}}$ \\
\hline YMRS (mean \pm SD) & & $2.5 \pm 2.8$ & $2.8 \pm 3.0$ & $2.0 \pm 2.3$ & & $0.41^{\mathrm{a}}$ \\
\hline Lithium yes/no & & $15 / 24$ & & & & \\
\hline Lithium level $(\mathrm{mmol} / \mathrm{l})($ mean $\pm \mathrm{SD})$ & & & $0.0 \pm 0.0$ & $0.7 \pm 0.2$ & & $<0.0005^{\mathrm{a}}$ \\
\hline Other mood stabilizers yes/no & & $11 / 28$ & $2 / 22$ & $9 / 6$ & & $<0.0005^{\mathrm{b}}$ \\
\hline Antipsychotics no/first/second generation & & $20 / 4 / 14$ & $13 / 2 / 9$ & $7 / 2 / 5$ & & $0.85^{\mathrm{b}}$ \\
\hline Antidepressants yes/no & & $14 / 25$ & $9 / 15$ & $5 / 10$ & & $0.79^{\mathrm{b}}$ \\
\hline $\begin{array}{l}\text { Family history depression, bipolar/other } \\
\text { psychiatric diagnosis/none }\end{array}$ & & $9 / 7 / 24$ & $5 / 2 / 16$ & $4 / 5 / 6$ & & $0.11^{\mathrm{b}}$ \\
\hline Prior psychotic symptoms (yes/no) & & $29 / 10$ & $16 / 8$ & $13 / 2$ & & $0.16^{\mathrm{b}}$ \\
\hline
\end{tabular}

MADRS Montgomery Asberg Depression Scale, YMRS Young Mania Rating Scale, $m$ mean, $S D$ standard deviation

a $P$ values (two tailed) based on ANOVA

b $P$ values (two tailed) based on exact $\chi^{2}$ tests

boundaries. As limits we used the interne capsule laterally, the third ventricle medially, ventrally the hypothalamus and dorsally the second ventricle. In the following step, the first visible part of the thalamus was detected in the coronary level. As orientation points, we used the abovedescribed marks and the Luschka foramen. The thalamus was marked in each slice in a frontooccipital direction. The two adjacent levels were used as controls. Total grey matter volume refers to the grey matter volume of the entire brain. After the segmentation of grey and white matter and cerebrospinal fluid by means of the freely available Statistical Parametrical Mapping Program (SPM99) of the Wellcome Trust Centre for Neuroimaging, the total grey matter was calculated automatically using our own algorithm. Relative volume was computed by dividing thalamus volume to the total grey matter volume.

Statistical analysis

For statistical analyses, SPSS 15 for Windows was used. Significance level was $\alpha=0.05$. All tests were two tailed.
Dependent variables were right and left relative thalamus volumes and total grey matter volume, independent variable was diagnostic group (bipolar patients, healthy controls).

\section{Identifying intervening covariates and factors}

Two-way analysis of variance (ANOVA) adjusted for diagnostic group was used to determine if there were significant influences on the dependent variables of gender or hand preference. Bivariate product moment correlations were calculated separately for control subjects and bipolar patients intending to analyse if age and duration of education had an influence on the dependent variables.

\section{Effect of diagnosis}

Analysis of covariance (ANCOVA) was computed to analyse if there were significant diagnosis differences for total grey matter volume. This analysis was performed with 
the independent factors diagnosis and gender and the covariates age and duration of education. As gender, age, education and hand preference showed no significant impact on thalamus volumes, univariate ANOVA with factor diagnosis and no other intervening variables were performed to determine whether there were differences between bipolar patients and controls for right and left relative thalamus volume.

\section{Effect of lithium, other medication and clinical variables}

The three groups, bipolar patients with lithium treatment, without lithium treatment and healthy controls, were compared on thalamic volume differences with ANOVA and subsequent two-group comparisons using Bonferroni' adjusted $P$ values.

An ANOVA design was applied to analyse if there was a significant impact of mood stabilizers other than lithium, psychotic symptoms or antipsychotic drugs. Pearson correlations were computed to analyse if disease duration, age at onset of the disease and the number of previous depressive or manic episodes had an influence on thalamic volumes.

\section{Results}

Identifying intervening covariates and factors

With respect to gender, statistical tests showed significantly ( $F=7.1, d f=1,8, P=0.009)$ more total grey matter in male subjects, but no significant differences regarding the left and right relative thalamus volume. No significant effect of hand preference on total grey matter volume or thalamus volume was detected, but a correlation was found between education and total grey matter volume (controls $r=0.6, P<0.0005$, bipolar patients $r=0.4, P=0.008$ ). Total grey matter volume showed a significant negative correlation with age (controls $r=-0.5, P=0.001$, bipolar patients $r=-0.5 P=0.003$ ), but there was no significant correlation of age with the relative thalamus volume.

\section{Effect of diagnosis}

Grey matter volume was not significantly different between the two diagnostic groups. In addition, there was no significant difference in thalamus volume between patients with bipolar I disorder and healthy controls. However, there was a trend for a volume decrease in bipolar patients for the left relative thalamus volume $(F=3.5, d f=1,8$, $P=0.066)$.

Effect of lithium, other medication and clinical variables

There were no significant differences in demographic variables between patients treated with lithium $(N=15)$ and those not receiving a lithium medication $(N=24)$ (see Table 1). In a three-group analysis, the factor lithium showed a significant influence on the relative right thalamus volume in patients with bipolar I disorder $(F=3.4$, $d f=2,8, P=0.040$ ). A subgroup analysis with Bonferroni adjustment for three comparisons showed a significant decrease in right thalamus volume in patients not treated with lithium as compared to healthy controls $(P=0.036)$. The lithium-treated patients showed no difference in thalamus volume as compared to the sample of healthy controls or the patients not treated with lithium (see Tables 2, 3, see Fig. 1). No impact of lithium on the grey matter volume could be detected.

Mood stabilizers other than lithium showed no significant influence on relative thalamic volumes. Amongst bipolar patients, there was no significant thalamus volume difference between patients with and without psychotic symptoms. Total grey matter volume was significantly decreased in patients treated with antipsychotic drugs $(P=0.023)$, but there was no significant influence of

Table 2 Thalamus volume divided by psychiatric diagnosis ( $P$ values based on ANOVA results)

\begin{tabular}{|c|c|c|c|c|c|c|}
\hline & $\mathrm{HC}$ & $\mathrm{BP}$ & Diff. \% BP versus $\mathrm{HC}$ & $d f$ & $F$ & $P$ \\
\hline All individuals $(N)$ & 41 & 41 & & & & \\
\hline Grey matter volume $\left(\mathrm{cm}^{3}\right.$ mean $\left.\pm \mathrm{SD}\right)(\mathrm{GM})$ & $713.8 \pm 71.6$ & $725.1 \pm 77.8$ & 1.6 & 1,8 & 1.2 & 0.50 \\
\hline \multicolumn{7}{|l|}{ Absolute thalamus volume } \\
\hline Right $\left(\mathrm{cm}^{3}\right.$ mean $\left.\pm \mathrm{SD}\right)$ & $6.88 \pm 0.87$ & $6.68 \pm 0.80$ & -3.0 & 1,8 & 1.2 & 0.27 \\
\hline Left $\left(\mathrm{cm}^{3}\right.$ mean $\left.\pm \mathrm{SD}\right)$ & $6.71 \pm 0.82$ & $6.59 \pm 0.86$ & -1.8 & 1,8 & 0.4 & 0.51 \\
\hline \multicolumn{7}{|l|}{ Relative thalamus volume (thalamus/GM) } \\
\hline Right $(\%$ of GM mean \pm SD) & $0.97 \pm 0.11$ & $0.92 \pm 0.10$ & -4.3 & 1,8 & 3.5 & 0.066 \\
\hline Left $(\%$ of GM mean \pm SD) & $0.94 \pm 0.10$ & $0.91 \pm 0.10$ & -3.3 & 1,8 & 2.1 & 0.15 \\
\hline
\end{tabular}

$H C$ healthy controls, $B P$ bipolar patients, $N$ number, $m$ mean, $S D$ standard deviation, Diff. $\%$ difference in percent terms 
Table 3 Thalamus volume divided by psychiatric diagnosis/bipolar patients with lithium-(Li) versus without lithium treatment (non-Li)

\begin{tabular}{|c|c|c|c|c|c|c|c|c|c|c|}
\hline & \multirow[t]{2}{*}{$\mathrm{HC}$} & \multicolumn{2}{|l|}{ BP, subsample } & \multicolumn{3}{|c|}{$\begin{array}{l}\text { Factor } \\
\text { diagnosis/LiBP }\end{array}$} & \multirow{2}{*}{$\begin{array}{l}\text { Non-LiBP } \\
\text { versus HC } \\
\text { Diff. \% }\end{array}$} & \multirow{2}{*}{$\begin{array}{l}\text { Non-Li } \\
\text { versus } \\
\mathrm{HC}, P\end{array}$} & \multirow{2}{*}{$\begin{array}{l}\text { BP Li } \\
\text { versus } \\
\text { HC Diff. \% }\end{array}$} & \multirow{2}{*}{$\begin{array}{l}\mathrm{BP} \mathrm{Li} \\
\text { versus } \\
\mathrm{HC}, P\end{array}$} \\
\hline & & Non-Li & $\mathrm{Li}$ & $d f$ & $F$ & $P$ & & & & \\
\hline All individuals $(N)$ & 41 & 24 & 15 & & & & & & & \\
\hline $\begin{array}{l}\text { Grey matter volume } \\
\quad\left(\mathrm{cm}^{3} \text { mean } \pm \mathrm{SD}\right)(\mathrm{GM})^{\mathrm{a}}\end{array}$ & $713.8 \pm 71.6$ & $729.0 \pm 74.6$ & $722.8 \pm 87.1$ & 2,70 & 0.8 & 0.46 & 2.1 & 1.0 & 1.3 & 0.58 \\
\hline \multicolumn{11}{|l|}{ Absolute thalamus volume $^{\mathrm{a}}$} \\
\hline Right $\left(\mathrm{cm}^{3}\right.$ mean $\left.\pm \mathrm{SD}\right)$ & $6.88 \pm 0.87$ & $6.54 \pm 0.86$ & $6.83 \pm 0.70$ & 2,70 & 3.6 & 0.031 & -4.9 & 0.082 & -0.8 & 1.00 \\
\hline Left $\left(\mathrm{cm}^{3}\right.$ mean $\left.\pm \mathrm{SD}\right)$ & $6.71 \pm 0.82$ & $6.47 \pm 0.86$ & $6.74 \pm 0.91$ & 2,70 & 2.7 & 0.072 & -3.6 & 0.1 & 0.5 & 0.97 \\
\hline \multicolumn{11}{|c|}{ Relative thalamus volume [thalamus/GM (\%)] ${ }^{\mathrm{b}}$} \\
\hline Right ( $\%$ of GM mean \pm SD) & $0.97 \pm 0.11$ & $0.90 \pm 0.10$ & $0.95 \pm 0.08$ & 2,77 & 3.4 & 0.040 & -6.9 & 0.036 & -1.7 & 1.00 \\
\hline Left $(\%$ of GM mean $\pm \mathrm{SD})$ & $0.94 \pm 0.10$ & $0.89 \pm 0.11$ & $0.94 \pm 0.08$ & 2,77 & 2.3 & 0.11 & -5.5 & 0.11 & -0.8 & 1.00 \\
\hline
\end{tabular}

$H C$ healthy controls, $B P$ bipolar patients, $N$ number, $m$ mean, $S D$ standard deviation, Diff. \% difference in per cent terms

$P$ values for the subgroup analyses were Bonferroni adjusted for three comparisons

a Analysis method: ANCOVA (factors diagnosis/lithium, covariates age, duration of education)

b Analysis method: ANOVA (factor diagnosis/lithium)
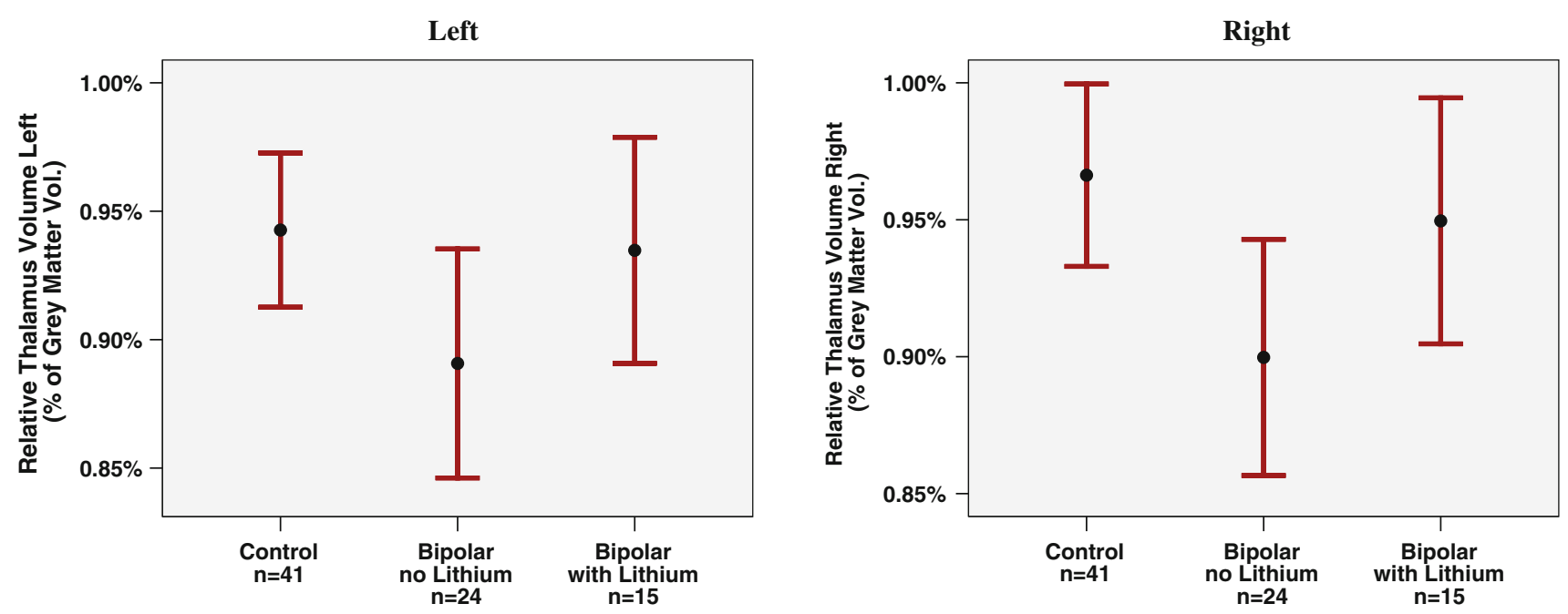

Fig. 1 Relative thalamus volume in bipolar patients with and without lithium treatment and controls. Figure 1 shows the mean and the 95\% confidence intervals as error bars of control subjects and bipolar patients without and with lithium treatment

antipsychotic drugs on left or right thalamus volume. There were no significant correlations between relative thalamus volumes and the duration of the disease, the age of onset and the number of previous depressive or manic episodes.

\section{Discussion}

In this study, we investigated the thalamus volume in patients with bipolar I disorder treated with or without lithium as compared to a well-matched group of healthy control subjects. We found a significantly decreased relative right thalamus volume in lithium-free bipolar patients in contrast to healthy controls, whereas the lithium-treated bipolar patients showed no difference to the thalamus volume of the healthy control group. No significant differences concerning the thalamus volume were detected between the whole patient group and control subjects.

These results are consistent with those of Foland et al. who recently reported an increase in the volume of hippocampus and amygdala in patients treated with lithium in comparison to those without such treatment [7]. With respect to the thalamus, Monkul et al. [13] showed an enlargement trend for the left thalamus in lithium-treated youths and adolescents in comparison to a lithium-free group of patients. Comparing patients with treatment including lithium or valproic acid with patients not receiving these substances, Chang et al. [4] also observed a 
trend for a larger left thalamus in the lithium or valproic acid-treated patients. In contrast, one study did not show any difference between lithium-treated patients and those not treated with lithium, but included only a relatively small number of patients [3].

Taken together, there are not many studies which use psychiatric medication, in particular mood stabilizers, as a variable within the analysis of structural findings in bipolar patients, although several studies investigated the effect of psychotropic medication and antipsychotics in particular in patients with schizophrenia [20]. The effect of psychotropic medication on grey matter though has been described as a possible cause for discrepancies in structural findings in bipolar patients. In our study, we detected a significantly decreased total grey matter volume in patients treated with antipsychotics. We assume that the effects of antipsychotics in bipolar patients would be similar to those in patients suffering from schizophrenia [20]. Nevertheless, as only four of our patients received first-generation antipsychotics, it has to be considered that the reduction in the total grey matter of the overall bipolar sample is due to factors yet unknown. Concerning mood stabilizers especially the role of lithium in a patients' medication seems to be crucial: Patients treated with lithium showed a significantly increased volume of grey matter [16, 18], an effect we were not able to detect in our study. A recently performed meta-regression showed that grey matter volume increased amongst patients with bipolar disorder when compared with controls when the proportion of patients using lithium increased [10]. A neurotrophic effect of lithium has been postulated [1], and the question raised as to whether lithium exerts great effects in discrete brain regions that have previously been associated with brain atrophy [16]. Moore et al. [17] even revealed significant differences in regional analyses between responders and non-responders to a lithium treatment: amongst bipolar patients only responders showed a significant increase in the grey matter volume in the prefrontal cortex and at trend level an increase in volume in the left subgenual prefrontal cortex.

A study by Scherk et al. [21] using voxel-based morphometry did not reveal any significant correlations of grey or white matter volume with lithium, mood stabilizers or antipsychotics. Using the same method Monkul et al. [14] showed no effect on total brain and total grey matter volume but a significant increase in the total white matter and the grey matter volume of the left and right dorsolateral prefrontal cortex and the left anterior cingulate after a 4 weeks lithium administration in healthy individuals. Another VBM study showed that lithium-treated patients have a regional grey matter loss in the left middle-occipital gyrus as compared to healthy controls and decreased grey matter in right orbital gyrus as compared to patients not taking lithium [6]. The authors suggested that regional effects exerted by lithium might be unrelated to its neurotrophic effects.

So far, there is not much knowledge about the mode of functioning of lithium at a molecular level. It was postulated to increase the neuropil, the volume of grey matter and to induce higher NAA concentrations $[1,16,18]$. However, the exact mechanism remains unknown. Studies suggest that it works at the molecular level to boost factors such as, bcl-2 [5], a cytoprotective protein which has neurotrophic effects and improves axon regeneration [16], brain-derived neurotrophic factor and provides a protection against stress-induced reductions in neuronal integrity [11, 27]. A protection of neural progenitor cells from apoptosis is also described [22]. How these changes exactly work to impact brain morphology and stabilize mood is unknown. According to former studies and to our results, lithium might exert a specific effect on a central region of human emotional processing and should, therefore, be particularly considered in the investigation of bipolar disorder.

The generally heterogeneous results in structural imaging of the thalamus volume described in the introduction could be due to several methodical limitations, e.g. the inclusion of patients with differing severity of symptoms, different affective states, first-episode and chronically ill patients into the same studies. Sometimes co-morbid alcohol or substance misuse was ignored or the patients' medication not considered. As mentioned in the introduction changes in volume of brain structure may underlie more differentiated modulation procedures than solely the diagnosis of a bipolar affective disorder [29]. In this point, especially the role of medication seems essential. To reduce the possible influence of concomitant factors, we included only euthymic patients with bipolar I disorder with no history of alcohol abuse or dependence and investigated a sufficiently large sample. All patients were treated with stable medication over several months. Another strength of our study is the presence of a healthy group of well-matched control subjects which is missing in the above-mentioned study of Foland et al. [7]. A limitation of our study is that the findings are the results of a transverse section and not of a longitudinal analysis. In addition, it was not possible to provide more detailed information about the exact duration of the lithium and antipsychotic treatment of the respective patients and for what reason the sample of the lithium-free patients had never received this medication. Future studies including larger numbers of patients might show a difference in thalamus volumes between the groups of patients treated or not treated with lithium which we were not able to demonstrate in our study.

Taken together, the present findings are consistent with the view that treatment with lithium may normalise right 
thalamus volume which is decreased without lithium treatment in bipolar I disorder. Further longitudinal studies are needed to clarify the role of thalamus volume in bipolar disorder and the influence effect of lithium on it.

Acknowledgments This study was supported by a Grant from the Saarland University Hospital, Germany to HS (HOMFOR A/2003/21).

\section{Conflict of interest statement None.}

Open Access This article is distributed under the terms of the Creative Commons Attribution Noncommercial License which permits any noncommercial use, distribution, and reproduction in any medium, provided the original author(s) and source are credited.

\section{References}

1. Bearden CE, Thompson PM, Dalwani M, Hayashi KM, Lee AD, Nicoletti M, Trakhtenbroit M, Glahn DC, Brambilla P, Sassi RB, Mallinger AG, Frank E, Kupfer DJ, Soares JC (2007) Greater cortical gray matter density in lithium-treated patients with bipolar disorder. Biol Psychiatry 62:7-16

2. Benke T, Kurzthaler I, Schmidauer C, Moncayo R, Donnemiller E (2002) Mania caused by a diencephalic lesion. Neuropsychologia 40:245-252

3. Caetano SC, Sassi R, Brambilla P, Harenski K, Nicoletti M, Mallinger AG, Frank E, Kupfer DJ, Keshavan MS, Soares JC (2001) MRI study of thalamic volumes in bipolar and unipolar patients and healthy individuals. Psychiatry Res 108:161-168

4. Chang K, Karchemskiy A, Barnea-Goraly N, Garrett A, Simeonova DI, Reiss A (2005) Reduced amygdalar gray matter volume in familial pediatric bipolar disorder. J Am Acad Child Adolesc Psychiatry 44:565-573

5. Chen G, Zeng WZ, Yuan PX, Huang LD, Jiang YM, Zhao ZH, Manji HK (1999) The mood-stabilizing agents lithium and valproate robustly increase the levels of the neuroprotective protein bcl-2 in the CNS. J Neurochem 72:879-882

6. Chen X, Wen W, Malhi GS, Ivanovski B, Sachdev PS (2007) Regional gray matter changes in bipolar disorder: a voxel-based morphometric study. Aust N Z J Psychiatry 41:327-336

7. Foland LC, Altshuler LL, Sugar CA, Lee AD, Townsend J, Narr KL, Asuncion DM, Toga AW, Thompson PM (2008) Increased volume of the amygdala and hippocampus in bipolar patients treated with lithium. Neuroreport 19:221-224

8. Inzelberg R, Nisipeanu P, Joel D, Sarkantyus M, Carasso RL (2001) Acute mania and hemichorea. Clin Neuropharmacol 24:300-303

9. Jones EG (1997) Cortical development and thalamic pathology in schizophrenia. Schizophr Bull 23:483-501

10. Kempton MJ, Geddes JR, Ettinger U, Williams SC, Grasby PM (2008) Meta-analysis, database, and meta-regression of 98 structural imaging studies in bipolar disorder. Arch Gen Psychiatry 65:1017-1032

11. Manji HK, Quiroz JA, Payne JL, Singh J, Lopes BP, Viegas JS, Zarate CA (2003) The underlying neurobiology of bipolar disorder. World Psychiatry 2:136-146
12. McDonald C, Zanelli J, Rabe-Hesketh S, Ellison-Wrigh I, Sham P, Kalidindi S, Murray RM, Kennedy N (2004) Meta-analysis of magnetic resonance imaging brain morphometry studies in bipolar disorder. Biol Psychiatry 56:411-417

13. Monkul ES, Nicoletti MA, Spence D, Sassi RB, Axelson D, Brambilla P, Hatch JP, Keshavan M, Ryan N, Birmaher B, Soares JC (2006) MRI study of thalamus volumes in juvenile patients with bipolar disorder. Depress Anxiety 23:347-352

14. Monkul ES, Matsuo K, Nicoletti MA, Dierschke N, Hatch JP, Dalwani M, Brambilla P, Sassi RB, Mallinger AG, Soares JC (2007) Prefrontal gray matter increases in healthy individuals after lithium treatment: a voxel based morphometry study. Neurosci Lett 429:7-11

15. Montgomery SA, Asberg M (1979) A new depression scale designed top be sensitive to change. Br J Psychiatry 134:382-389

16. Moore GJ, Bebchuk JM, Wilds IB, Chen G, Manji HK (2000) Lithium-induced increase in human brain grey matter. Lancet 356:1241-1242

17. Moore GJ, Cortese BM, Glitz DA, Zajac-Benitez C, Quiroz Ja, Uhde TV, Drevets WC, Manji HK (2009) A longitudinal study on the effects of lithium treatment on prefrontal and subgenual prefrontal gray matter volume in treatment-responsive bipolar disorder patients. J Clin Psychiatry 70:669-705

18. Sassi RB, Nicoletti M, Brambilla P, Mallinger AG, Frank E, Kupfer DJ, Keshavan MS, Soares JC (2002) Increased gray matter volume in lithium-treated bipolar disorder patients. Neurosci Lett 329:243-245

19. Scherk H, Reith W, Falkai P (2004) Changes in brain structure in bipolar affective disorders. Nervenarzt 75:861-872

20. Scherk H, Falkai P (2006) Effect of antipsychotics on brain structure. Curr Opin Psychiatry 19:145-150

21. Scherk H, Kemmer C, Usher J, Reith W, Falkai P, Gruber O (2008) No change to grey and white matter volumes in bipolar I disorder patients. Eur Arch Psychiatry Clin Neurosci 258:345349

22. Shimomura A, Nomura R, Senda T (2003) Lithium inhibits apoptosis of mouse neural progenitor cells. Neuroreport 14:17791782

23. Soares JC, Mann JJ (1997) The functional neuroanatomy of mood disorders. J Psychiatr Res 31:393-432

24. Strakowski SM, DelBello MP, Adler CM (2005) The functional neuroanatomy of bipolar disorder: a review of neuroimaging findings. Mol Psychiatry 10:105-116

25. Verhagen WI, Huygen PL, Dalman JE, Schuurmans MM (1996) Whipple's disease and the central nervous system: a case report and a review of the literature. Clin Neurol Neurosurg 98:299-304

26. Wittchen HU, Zaudig M, Fydrich T (1997) Strukturiertes klinisches Interview für DSM-IV. Achse I und Achse II. Handanweisung. Hogrefe, Göttingen

27. Wood GE, Young LT, Reagan LP, Chen B, McEwen BS (2004) Stress-induced structural remodeling in hippocampus: prevention by lithium treatment. Proc Natl Acad Sci USA 101:3973-3978

28. Young RC, Biggs JT, Ziegler VE, Meyer DA (1978) A rating scale for mania: reliability, validity and sensitivity. Br J Psychiatry 133:429-435

29. Zanetti MV, Jackowski MP, Versace A, Almeida JR, Hassel S, Duran FL, Busatto GF, Kupfer DJ, Phillips ML (2009) Statedependent microstructural white matter changes in bipolar I depression. Eur Arch Psychiatry Clin Neurosci 259:316-328 